A. KOVÁČOVÁ*\#, T. KVAČKAJ*, R. BIDULSKÝ*, J. BIDULSKÁ*, R. KOČIŠKO*,

J. DUTKIEWICZ**, L. LITYŃSKA-DOBRZYŃSKA**

\title{
INVESTIGATION OF THE ULTRAFINE-GRAINED STRUCTURE FORMATION UNDER DIFFERENT STRAIN RATES
}

\begin{abstract}
The present paper deals with a study on formation of specific substructural features in OFHC copper processed by equalchannel angular pressing (ECAP) considering different strain rate conditions. Since two mechanical tensile testing equipments were being used, strain rate response could be studied in a wide range (both in static and dynamic regimes). Moreover, the copper before tensile testing was subjected to drawing and ECAP, separately, which allows to study the influence of both structural and substructural features (CG vs. UFG structure). Considering the static regime, it was found that UFG materials have advanced properties, showing higher strength and ductility in comparison to their CG counterparts. However, this is valid only to the critical value of the strain rate. In the dynamic regime, mathematical linearized results imply that ultimate tensile strength in samples processed by ECAP increases twice every $10 \mathrm{~s}^{-1}$ rising, however, they lost approximately the same plastic properties than samples after drawing. Differences in the progress of mechanical properties are related to specific structural and substructural features evolved in the material during ECAP processing. Above mentioned features were studied in detail by methods of transmission and scanning electron microscopy (TEM, SEM).

Keywords: electron microscopy, EBSD, nanostructured materials, equal channel angular processing, grain refinement
\end{abstract}

\section{Introduction}

Copper is a promising material which offers a lot of structural applications working in different strain rate conditions. To examine the material strain rate response (strengthening characteristics, resistance to failure), testing of a material has to be carried out in a wide range of loading rates. Therefore, different techniques have been used: a) quasi-static strain rate tests $\left(10^{-3}-10^{-1} \mathrm{~s}^{-1}\right)$ have been performed using a conventional mechanical tensile testing apparatus; b) intermediate strain rate tests $\left(10^{1}-10^{2} \mathrm{~s}^{-1}\right)$ using an instrumented falling weight apparatus; and (c) high strain rates (above $10^{3} \mathrm{~s}^{-1}$ ) using a tensile split Hopkinson bar [1]. Conventional mechanical tensile testing apparatus and split Hopkinson bar techniques have been popular and currently used to experimental material investigation in quasi-static and high strain rates [2-5]. On the other hand, works describing the influence of intermediate strain rates on material properties have been insufficiently available, nowadays.

The influence of strain rate on material properties is still the objective of scientific interest, however, most studies are focused on materials prepared by conventional metal working methods $[1,6]$. Severe plastic deformation (SPD) methods provide refining the material internal structure to the submicrometer range in order to improve material properties. Ultrafine-grained (UFG) material is as a material with average grain size in a range of $1-0,1 \mu \mathrm{m}$ and advanced properties as high strength, suitable ductility [7,8], good corrosion resistance [9]. In recent years, a lot of different SPD processing techniques have been developed, as equal-channel angular pressing (ECAP) [10-13], high pressure torsion (HPT) [14-16], accumulative roll - bonding (ARB) $[17,18]$, equal-channel angular rolling (ECAR) $[19,20]$ and [21], ECAP - Conform [22] and others.

Equal-channel angular pressing (ECAP) is an attractive and relatively simple technique that was developed by Segal and his co-workers $[23,24]$. Through the ECAP processing, a sample is being pressed through a die without changes of geometrical parameters. The construction of an ECAP die allows to impose high strains and to develop a simple shear in a sample [10,12,25-32]. However, it has to be noted that the deformation mechanism and material structure evolved during SPD processing show specific features behaving differently than during the processing through conventional metal forming processes $[12,33,34]$.

According to some authors [35], the development of microstructural features following severe plastic deformation methods differs from conventional cold working techniques. During SPD processing, microstructural evolution is related to subgrain formation, evolution of the cells, types of boundaries, nucleation and growth processes, as well as dislocation behaviour. Moreover, 
other authors [33] imply that the deformation mechanisms in UFG materials include slip of perfect and partial dislocations, deformation twinning, stacking faults, grain-boundary sliding, and grain rotations. These deformation mechanisms also exist in coarse-grained (CG) materials however their behaviour is different. Such features as a change in dislocation density, formation of ultrafine grains and reduction of grain size during SPD processes can improve final material mechanical properties [36]. To study deformation processes and microstructural evolution during ECAP, copper is a suitable material because of FCC structure, medium stacking fault energy with a long research history [37].

The aim of this paper is to analyse the mechanical behaviour of OFHC copper in different strain rates conditions. As OFHC copper was subjected to drawing and equal-channel angular pressing (ECAP) that was able to compare conventional and new-progressive metal working methods. Moreover, since two different tensile testing apparatuses were used (resulting in a wide strain rates range $\sim 10^{-3}-10^{2} \mathrm{~s}^{-1}$ ), the influence of intermediate strain rates on material properties in UFG copper has been rarely studied. Hence, it is of great interest to focus on this topic. Furthermore, detailed microstructural and substructural analysis was performed by transmission electron microscopy (TEM) and electron backscattered diffraction (EBSD).

\section{Material and methods}

OFHC copper with purity above $99.99 \%$ and an initial grain diameter $40 \mu \mathrm{m}$ was used in this study. Two methods (drawing and ECAP) were applied to form coarse-grained (CG) and ultrafine-grained (UFG) structures in samples, respectively. During the drawing process, samples were drawn from diameter $15 \mathrm{~mm}$ to $10 \mathrm{~mm}$. During ECAP, samples in a cylindrical cross section (diameter $10 \mathrm{~mm}$, length $100 \mathrm{~mm}$ ) were subjected to 5 passes and rotated according to a route $\mathrm{C}$ using a die having $\varphi=90^{\circ}, \psi=0^{\circ}$. Both methods were applied at room temperature.

The influence of strain rate on material properties was studied in a wide strain rate range namely in conditions - static $\left(\dot{\varepsilon} \sim 10^{-3}-10^{-1} \mathrm{~s}^{-1}\right)$ and dynamic $\left(\dot{\varepsilon} \sim 10^{2} \mathrm{~s}^{-1}\right)$. To study properties, two different equipments were used - tensile testing machine Labtest 5.20 with strain gauge and rotating flywheel machine with piezoelectric detector, as well. Tensile tests were performed at room temperature. EBSD, TEM analysis were carried out using scanning electron microscope PHILIPS XL30 and transmission electron microscope JEOL JEM 2000 FX, respectively. The experimental results were processed by mathematical analysis.

\section{Results}

The load - displacement and load - time dependencies were registered in static and dynamic testing conditions, respectively. According to the curves, mechanical properties as tensile yield stress $\left(\sigma_{0.2}\right)$, ultimate tensile strength $\left(\sigma_{\mathrm{UTS}}\right)$ and reduction of area (RA) were determined.

\subsection{Static conditions}

During testing on a tensile machine, the speed of the instrument displacement varied what results in different strain rate conditions. The dependence of the mechanical properties on strain rate for samples processed by drawing and ECAP in static conditions is shown in Fig. 1. According to Fig. 1, values of yield stress imply no significant difference between drawing and ECAP methods. After ECAP, even from $\dot{\varepsilon} \sim 0.1 \mathrm{~s}^{-1}$, slight increase in yield stress was achieved. Moreover, values of yield stress were closed to each other for both drawing and ECAP states. However, the progress of ultimate tensile strength revealed greater influence of applied methods on properties. As is seen in Fig. 1, ultimate tensile strength was higher after ECAP processing to drawing. Considering the ratio between yield stress and ultimate tensile strength, copper with ultrafinegrained structure shows advanced plasticity. Moreover, the reduction of area was greater after ECAP processing (Fig. 2) however, only to a critical value of strain rate $\left(\dot{\varepsilon} \sim 0.06 \mathrm{~s}^{-1}\right)$. It is well-known and many times published [7-9] that UFG materials have advanced properties showing higher strength and ductility in comparison to their CG counterparts. However, according to the results mentioned above, this is applicable only to a critical value of strain rate. Besides, the mechanical properties were being enhanced after the ECAP processing which implies that the grain size refinement through SPD methods has positive impact on material properties what makes them attractive for industry. Moreover, Fig. 1 also offers an overview of the mechanical properties progress to strain rate in OFHC copper after drawing and ECAP processing within a range $\dot{\varepsilon} \sim 0.002-0.4 \mathrm{~s}^{-1}$. Considering the strain rate, strength properties are being increased while strain rate is increasing in both cases, it is also in agreement with conventional mechanical strengthening (with increasing strain rate). The progress in the reduction of area involved in applied methods on strain rate was not so obvious. While the strain rate is increasing during tensile loading, reduction of area after drawing increases but decreases after ECAP.

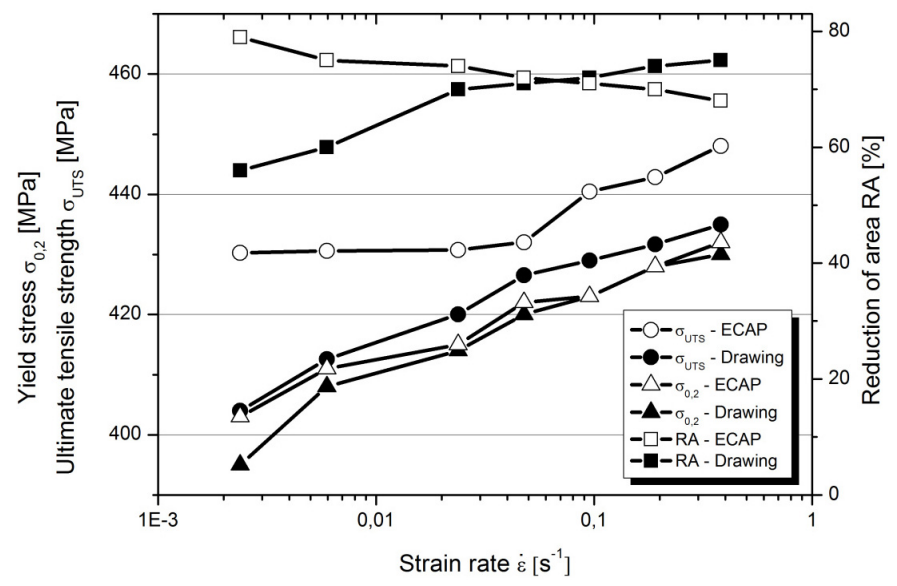

Fig. 1. Mechanical properties vs. strain rate in the static regime 


\subsection{Dynamic conditions}

Fig. 2 is an example displaying load and time progress during measuring in dynamic conditions [38]. The load and time progress indicates occurrence of the wave in the sample during measuring. The wave emerged on a detector which was noticed from a point indicated by the dashed arrow. The test ended when the load fell down to zero (continuous arrow line). The similar curves progress (as is seen in Fig. 3) emerged in the whole dynamic regime for both states (drawing, ECAP). Tensile yield stress was not established in the dynamic regime due to its nearly identical value to $\sigma_{\mathrm{UTS}}$.

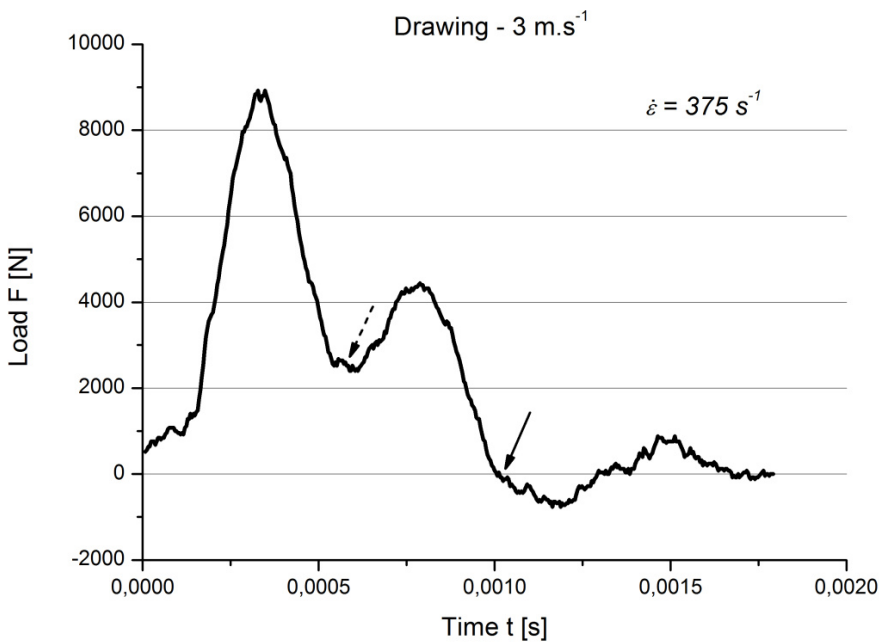

Fig. 2. The load-time dependence for the drawing state $(3 \mathrm{~m} / \mathrm{s})[38]$

Fig. 3 illustrates progress of mechanical properties on strain rate for samples after drawing and ECAP processing (CG vs. UFG) in the dynamic regime. UFG copper had greater strength but lower ductility than CG copper, however considering the increase in strength after ECAP, loss of the ductility is not significant enough. Besides, the reduction of area decreases with increasing strain rate for both states (drawing vs. ECAP). Moreover, in the dynamic regime, the curve displaying the ultimate tensile strength progress is more rapid than in the static regime that implies higher strain rate sensitivity.

The dependence between mechanical properties and strain rate in the dynamic regime was mathematically processed. It was found, the increase in strain rate resulted in mechanical properties as follows:

- drawing state: the increase in $\sigma_{U T S}$ about $4 \mathrm{MPa}, \mathrm{RA}$ decreases about $0,8 \%$ per $10 \mathrm{~s}^{-1}$.

- $\quad$ ECAP state: the increase in $\sigma_{U T S}$ about $8 \mathrm{MPa}, \mathrm{RA}$ decreases about $1 \%$ per $10 \mathrm{~s}^{-1}$.

The linearized results show that ultimate tensile strength of samples processed by ECAP after tensile testing in the dynamic regime increases twice every $10 \mathrm{~s}^{-1}$ increase in comparison to drawing, however, they lose approximately the same plastic properties. Hence, ultrafine-grained metallic materials are more sensitive on the strain rate compared to their coarse-grained counterparts what was also confirmed in the [39]. As the struc- ture of nanostructured materials includes ultra-fine grains that have low ability to accumulate dislocations in their interior, nanostructured materials provide high flow stresses but low work hardening rate $[40,41]$. Testing at high strain rates and/or low temperatures impedes annihilation of the dislocations on grain boundaries and thermally activated cross slip and climb [39] leading to the increasing work hardening rate and enhancing uniform elongation [42].

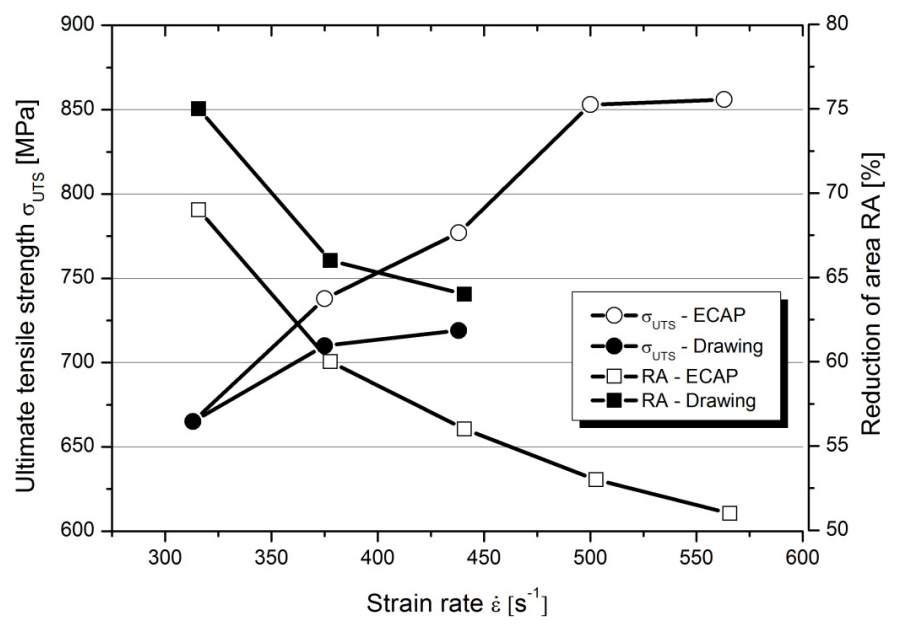

Fig. 3. Mechanical properties vs. strain rate in the dynamic regime

\section{Discussion}

It is well-known that material properties depend on their internal structure which is strongly affected by metal forming processes. It is highly unlikely, specific microstructural and substructural features evolved in materials during ECAP processing have a significant impact on the deformation mechanisms which are typically not operative in coarse-grained materials. Conventional metal working methods as drawing or rolling are not sufficient for obtaining the submicron grain sizes because of their limited straining capacity and impossibility in producing the substructures with high angle misorientations [12]. To overcome this limitation, a SPD method such as ECAP has been developed to produce the materials with UFG structures through the introduction of heavy strain on material without changes in a sample's cross-section. One of the specific features of materials processed by ECAP is grain refinement to a submicron level. Fig. 4 shows presence of the equiaxed ultrafine grains of diameter about $500 \mathrm{~nm}$ in copper after five ECAP passes.

Other specific feature of nanostructured materials are the structural misorienation changes evolving in a material during ECAP processing. Results from EBSD measurements were drawn to the graphical dependences as presented in Fig. 5. Fig. 5 clearly shows that the first ECAP pass causes increase in the low-angle grain boundaries fraction, consequently as far as the number of ECAP passes increase, a fraction of the high-angle grain boundaries is rising. Similar results in copper processed by ECAP were confirmed by the authors $[37,43]$. Such differences in the misorientation evolution of copper during the SPD 


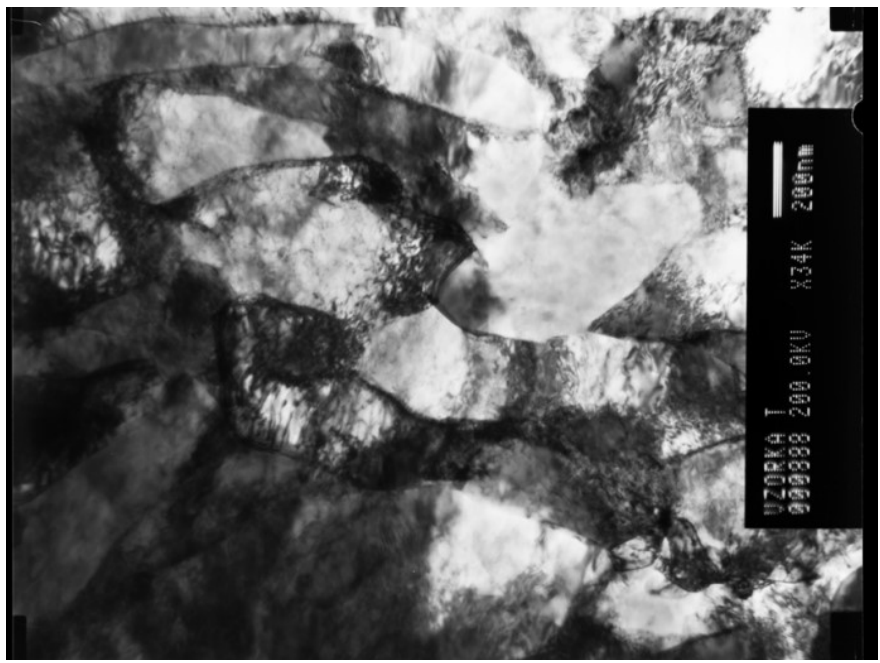

Fig. 4. TEM image of OFHC copper after five ECAP passes

processing can have positive impact on final properties [44]. According to some authors [45-48], heavy deformations (cold rolling or drawing) can result in the significant refinement of microstructure at low temperatures. However, the structures formed are usually substructures of a cellular type having boundaries with low angle misorientations. At the same time, nanostructures being formed during the SPD processing are ultrafine-grained structures of a granular type containing mainly high angle grain boundaries [49-51].

Except the formation of ultrafine grains and changes in the misorientation, the material structure processed by SPD methods includes other significant structural and substructural features. Fig. 6a shows that in copper processed by five ECAP passes, high dislocation density is observed. Lugo et. al [52] revealed the saturation of dislocation density in copper processed by five ECAP passes. High dislocation density can contribute to the overall increase in strength, on the other hand, it could be responsible for low ductility in ultrafine - grained materials [53]. At the same time, "non-equilibrium" grain boundaries are visible in ultrafine-grained structures. Their presence in copper processed by five ECAP passes were revealed and clearly shown in Fig. $6 \mathrm{~b}$ where extinction contours are presented (indicated by an arrow). The presence of extinction contours on TEM images is expression of the non-equilibrium grain boundary state [44]. The main features of the non-equilibrium grain boundary is excess of the grain boundary energy and long range elastic stresses, typically results from the interaction of lattice disloca-
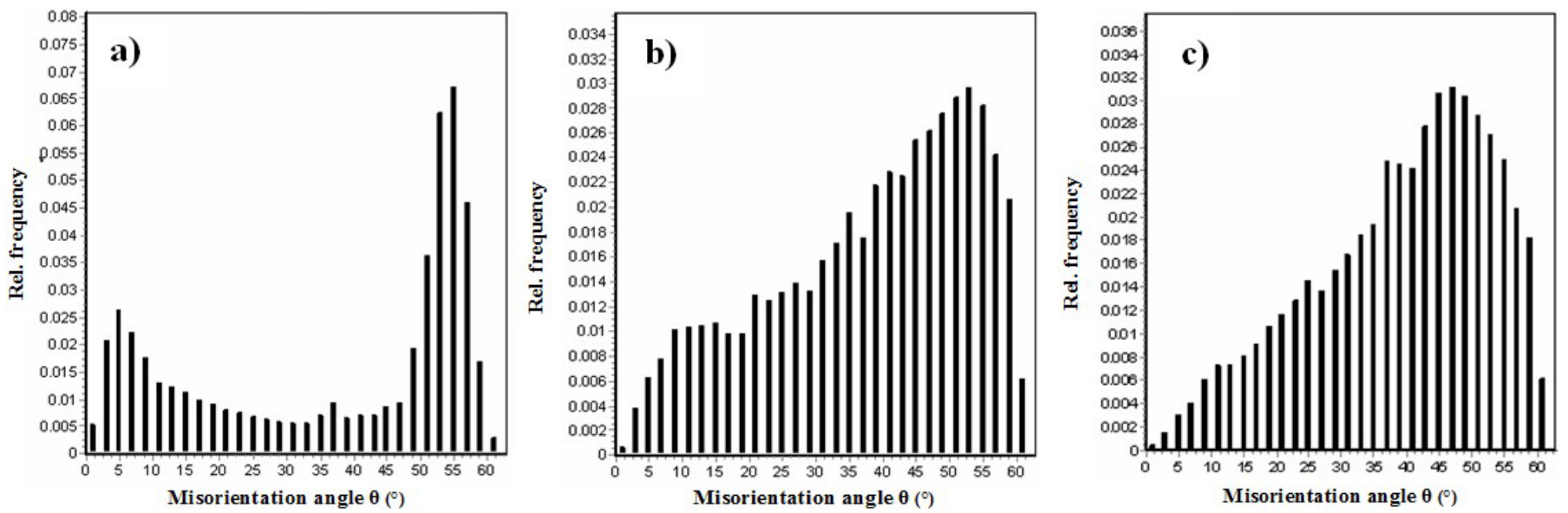

Fig. 5. The misorientation angles distribution in OFHC copper a) without ECAP b) one ECAP pass c) five ECAP passes
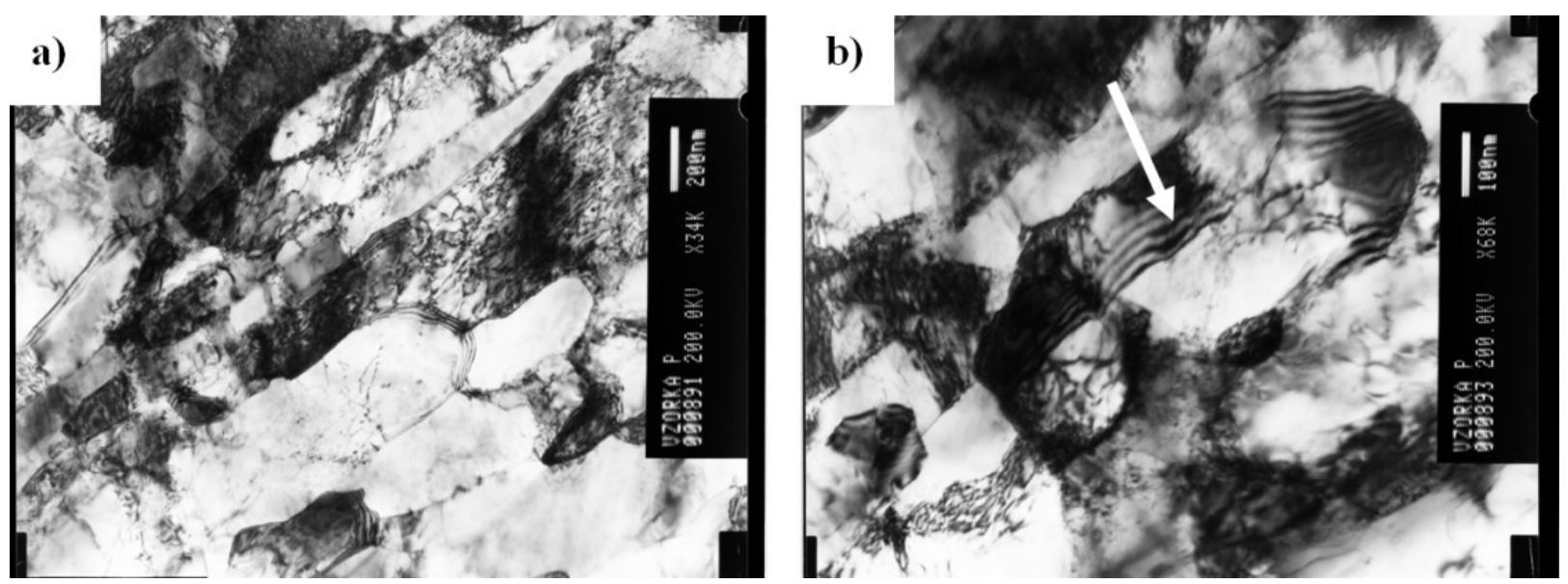

Fig. 6. TEM images of OFHC copper after five ECAP passes showing a) high dislocation density b) extinction contours implying the presence of non-equilibrium grain boundary 
tions and grain boundaries [44]. The authors [53] argued that the non-equilibrium grain boundaries lead to lower activation energy for grain boundary diffusion. Since grain boundary diffusion is responsible for Coble creep, presence of the non-equilibrium grain boundaries will enhance deformation processes controlled by the grain boundary diffusion and finally have a positive impact on the plasticity. Even, Kawasaki et al. [54] found the local small-scale grain boundary sliding in low temperatures in materials processed by ECAP. They have proposed that such grain boundary sliding is attributed to the occurrence of the non-equilibrium grain boundaries containing high densities of the extrinsic dislocations. Presence of the extrinsic dislocations in grain boundaries was also confirmed by Valiev et al. [44]. According to the experimental works [55-56], Kawasaki et al. have argued these extrinsic dislocations are being moved along grain boundaries and consequently cause localized sliding and this provides important difference in the flow characteristic between conventional metals and UFG metals prepared by SPD processing [54].

According to the previous experimental works [10,11,34] and aforementioned results, this study provides a model of the UFG structures formation in materials processed by SPD. The model describes formation of the UFG structures through presence of the cells (subgrains) in initial grains which are bounded with dislocation's walls having boundaries with low angle misorientations in early stages. Consequently, with further deformation, transformation of the subgrain boundaries with high density of the dislocations in to mainly high angle grain boundaries leads to the formation of ultrafine grains what was also confirmed by the author [44]. Valiev et al. [44] have been describing the transformation of the cellular structure to granular through partial annihilation of the dislocations with different signs in cell (subgrain) boundaries in the moment when the dislocation density in cell walls achieves a critical value [44,53]. Finally, excess in the dislocations with a single sign lead to increase of the misorientation with following transformation to the granular structure.

\section{Conclusions}

Conclusions are as follows:

- $\quad$ in both regimes (static and dynamic), strength properties (ultimate tensile strength, yield stress) were being increased with the strain rate increasing, independent from applied technology.

- $\quad$ in the static regime, plastic properties (reduction of area) in copper processed by drawing increased but on the other hand after ECAP processing, reduction of area decreased. in the dynamic regime, reduction of area being decreased in both cases (drawing, ECAP) with the strain rate increasing. regarding the static regime, it was found that UFG materials have advanced properties showing higher strength and ductility in comparison to their CG counterparts, however, this is valid only to a critical value of strain rate. in the dynamic regime, the mathematical linearized results imply that ultimate tensile strength in samples processed by ECAP after tensile testing in the dynamic regime increases twice each $10 \mathrm{~s}^{-1}$ increase however they lose approximately the same plastic properties than samples processed by drawing.

- differences in the progress of the mechanical properties are connected to specific microstructural and substructural features evolved in a material during ECAP processing.

\section{Acknowledgements}

This work is supported by the Slovak Agency APVV-20-027205 and the Project VEGA 1/0359/11.

\section{REFERENCES}

[1] I. Ulacia, C.P. Salisbury, I. Hurtado, M.J. Worswick, J. Mater. Process. Technol. 211, 830-839 (2011).

[2] R. Gerlach, S.K. Sathianathan, C. Siviour, N. Petrinic, Int. J. Impact Eng. 38, 976-980 (2011).

[3] A. Mishra, M. Martin, N.N. Thadhani, B.K. Kad, E.A. Kenik, M.A. Meyers, Acta Mater. 56, 2770-2783 (2008).

[4] I. Ulacia, N.V. Dudamell, F. Gálvez, S .Yi, M.T. Pérez-Prado, I. Hurtado, Acta Mater. 58, 2988-2998 (2010).

[5] B. Li, S.P. Joshi, O. Almagri, Q. Ma, K.T. Ramesh, T. Mukai, Acta Mater. 60, 1818-1826 (2012).

[6] R.R. Adharapurapu, F. Jiang, J.F. Bingert, K.S. Vecchio, Mater. Sci. Eng. A 527, 5255-5267 (2010).

[7] N. Krasilnikov, W. Lojkowski, Z. Pakiela, R. Valiev, Mater. Sci. Eng. A 397, 330-337 (2005).

[8] R. Valiev, Int. J. Mater. Res. 100, 757-761 (2009).

[9] B. Hadzima, M. Janecek, Y. Estrin, H.S. Kim, Mater. Sci. Eng. A 462, 243-247 (2007).

[10] T. Kvačkaj, A. Kováčová, M. Kvačkaj, I. Pokorný, R. Kočiško, T. Donič, Mater. Lett. 64, 2344-2346 (2010).

[11] A. Kovacova, T. Kvackaj, L. Litynska-Dobrzynska, J. Dutkiewicz, Chem. Listy 105, 523-525 (2011).

[12] R.Z. Valiev, T.G. Langdon, Prog. Mater. Sci. 51, 881-981 (2006).

[13] I. Bernathova, O. Milkovic, Chem. Listy 105, 645-646 (2011).

[14] N.A. Smirnova, V.I. Levit, V.I. Pilyugin, R.I. Kuznetsov, L.S. Davydova, V.A. Sazonova, Fiz. Met. Metalloved. 61, 1170-1177 (1986).

[15] R.Z. Valiev, O.A. Kaibyshev, R.I. Kuznetsov, R.Sh. Musalimov, N.K. Tsenev, Proc. USSR Acad. Sci. 301, 864-867 (1988).

[16] A.P. Zhilyaev, G.V. Nurislamova, B.K. Kim, M.D. Baro, J.A. Szpunar, T.G. Langdon, Acta Mater 51, 753-765 (2003).

[17] Y. Saito, N. Tsuji, H. Utsunomiya, T. Sakai, R.G. Hong, Scripta Mater. 39, 1221-1227 (1998).

[18] Y. Saito, H. Utsunomiya, N. Tsuji, T. Sakai, Acta Mater. 47, 579583 (1999).

[19] A. Habibi, M. Ketabchi, M. Eskandarzadeh, J. Mater. Process. Technol. 211, 1085-1090 (2011). 
[20] M. Kvackaj, T. Kvackaj, A. Kovacova, R. Kocisko, J. Bacso, Acta Metall. Slovaca 16, 84-90 (2010).

[21] T. Kvackaj, M. Kvackaj, V. Stoyka, R. Kocisko, J. Bidulska, J. Bacso, Mater. Sci. Forum 667-669, 133-137 (2011).

[22] G.J. Raab, R.Z. Valiev, T.C. Lowe, Y.T. Zhu, Mater. Sci. Eng. A 382, 30-34 (2004).

[23] V.M. Segal, V.I. Reznikov, A.E. Drobyshevskiy, V.I. Kopylov, Izvestia Akademii nauk SSSR, Metally 1, 115-123 (1981).

[24] V.M. Segal, USSR Patent No. 575892, 1977.

[25] M. Balog, F. Simancik, O. Bajana, G. Requena, Mater. Sci. Eng. A 504, 1-7 (2009).

[26] J. Bidulska, R. Kocisko, R. Bidulsky, M. Actis Grande, T. Donic, M. Martikan, Acta Metall. Slovaca 16, 4-11 (2010).

[27] R. Bidulsky, J. Bidulska, M. Actis Grande, High. Temp. Mater. Process. 28, 337-342 (2009).

[28] R. Kocisko, T. Kvackaj, J. Bidulska, M. Molnarova, Acta Metall. Slovaca 15, 228-233 (2009).

[29] A. Kovacova, T. Kvackaj, M. Kvackaj, I. Pokorny, J. Bidulska, J. Tiza, M. Martikan, Acta Metall. Slovaca 16, 91-96 (2010).

[30] T. Kvackaj, M. Zemko, R. Kocisko, T. Kuskulic, I. Pokorny, M. Besterci, K. Sulleiova, M. Molnarova, A. Kovacova, Kovove Mater. 45, 249-254 (2007).

[31] Z. Yang, U. Welzel, Mater. Lett. 27, 3406-3409 (2005).

[32] I. Bernáthová, O. Milkovič, Chem. Listy 105, 645-646 (2011).

[33] Y.T. Zhu, B.Q. Han, E.J. Lavernia, 2009. Deformation Mechanisms of Nanostructured Materials, in: M.J. Zehetbauer, Y.T. Zhu, (Eds.), Bulk Nanostructured Materials. WILEY-VCH Verlag GmbH \& Co. KGaA, Weinheim, pp. 89-108

[34] T. Kvačkaj, A. Kováčová, M. Kvačkaj, R. Kočiško, L. Litynska-Dobrzynska, V. Stoyka, M. Mihaliková, Micron 43, 720-724 (2012).

[35] E. Tan, A.A. Kibar, C.H. Gür, Mater. Charact. 62, 391-397 (2011).

[36] W. Wei, G. Chen, J. T. Wang, G. L. Chen, Rare Metals 25, 697-703 (2006).

[37] M. Janecek, J. Cizek, M. Dopita, R. Kral, O. Srba, Mater. Sci. Forum 584-586, 440-445 (2008).
[38] T. Kvackaj, A. Kovacova, J. Bidulska, R. Bidulsky, R. Kocisko, Arch. Metall. Mater. 60 (2), 605-614 (2015).

[39] Y.M. Wang, E. Ma, Acta Mater. 52, 1699-1709 (2004).

[40] Y. Zhao, Y.T. Zhu, E.J. Lavernia, Adv. Eng. Mater. 12, 769-778 (2010).

[41] E. Ma, JOM 58, 49-53 (2006).

[42] I. Sabirov, M.Yu. Murashkin, R.Z. Valiev, Mater. Sci. Eng. A 560, $1-24$ (2013)

[43] A. Mishra, V. Richard, F. Gregori, B. Kad, R.J. Asaro, M.A. Meyers, Mater. Sci. Forum 503-504, 25-30 (2006).

[44] R.Z. Valiev, R.K. Islamgaliev, I.V. Alexandrov, Prog. Mater. Sci. 45, 103-189 (2000).

[45] V.A. Pavlov, Phys. Met. Metallurg 67, 924-932 (1989).

[46] G. Langford, M. Cohen, Trans ASM 82, 623-638 (1969).

[47] V.V. Rybin, Large plastic deformations and destruction of metals, Metallurgia, Moscow, 1987.

[48] J. Gil Sevillano, P. Van Houtte, E. Aernoudt, Prog. Mater. Sci. 25, 69-134 (1980).

[49] R.Z. Valiev, editor. Ultrafine-grained materials prepared by severe plastic deformation, vol. 21, Annales de Chimie. Science des Materiaux, 1996, p. 369, Special issue.

[50] R.Z. Valiev, A.V. Korznikov, R.R. Mulyukov, Mater. Sci. Eng. A 168, 141-148 (1993).

[51] R.Z. Valiev, I.V. Alexandrov, R.K.Islamgaliev, Processing and Properties of Nanostructured Materials Prepared by Severe Plastic Deformation, In: G.M. Chow, N.I. Noskova, (eds.) Nanocrystalline materials, NATO ASI Series, 50, Springer, Netherlands, 1998, 121-142.

[52] N. Lugo, N. Llorca, J.J. Sunol, J.M. Cabrera, J. Mater. Sci. 45, 2264-2273 (2010).

[53] Y.T. Zhu, T.G. Langdon, Mater. Sci. Eng. A 409, 234-242 (2005).

[54] M. Kawasaki, N. Balasubramanian, T.G. Langdon, Mater. Sci. Eng. A 528, 6624-6629 (2011).

[55] Y.M. Wang, E. Ma, M.W. Chen, Appl. Phys. Lett. 80, 2395-2397 (2002).

[56] R.Z. Valiev, Nat. Mater. 3, 511-516 (2004). 